\title{
Fluorogenic Biosensors Constructed via Aggregation-induced Emission Based on Enzyme-catalyzed Coupling Reactions for Detection of Hydrogen Peroxide
}

\author{
Xiaogang LI, ${ }^{* 1, * 2}$ Wenxiu YU, ${ }^{* 3}$ Hongjie ZHAO, ${ }^{* 3}$ Zhiwen FAN, ${ }^{* 3}$ Meng XIAO, ${ }^{* 2, * 4}$ Rimo XI, ${ }^{* 3}$ \\ Yingchun $\mathrm{XU}, * 2, * 4 \dagger$ and Meng MENG ${ }^{* 3 \dagger}$ \\ *1 Medical Science Research Center, State Key Laboratory of Complex Severe and Rare Diseases, \\ Peking Union Medical College Hospital, Chinese Academy of Medical Science and Peking Union \\ Medical College, Beijing, China \\ *2 Beijing Key Laboratory for Mechanisms Research and Precision Diagnosis of Invasive Fungal Diseases, \\ Beijing, China \\ *3 College of Pharmacy, State Key Laboratory of Medicinal Chemical Biology, Nankai University, Tianjin 300353, \\ China \\ *4 Department of Clinical Laboratory, Peking Union Medical College Hospital, Peking Union Medical College \\ and Chinese Academy of Medical Sciences, Beijing, China
}

\begin{abstract}
Hydrogen peroxide $\left(\mathrm{H}_{2} \mathrm{O}_{2}\right)$ is a main reactive oxygen by-product produced in the metabolism of organisms and a common biomarker of oxidative stress. Aggregation-induced emission (AIE) probes for $\mathrm{H}_{2} \mathrm{O}_{2}$ have been proposed. Such AIEgens mostly use benzeneboronic acid as a recognition group. Recently, a strategy involving enzyme-catalyzed polymerization of AIE compounds shows great potential in AIEgens design. We herein modify the AIE motif, tetraphenylethene (TPE) with o-phenylenediamine (TPE-TAF), which can be oxidated by $\mathrm{H}_{2} \mathrm{O}_{2}$ in HRP to form an intramolecular phenazine structure. Compared with a similar approach, the proposed strategy is simple and the TPE-TAF showed a sensitive "turn-on" fluorescence with $\mathrm{H}_{2} \mathrm{O}_{2}$. The detection limit (LOD) is $3.39 \mu \mathrm{M}$ and the probe is highly specific against $\mathrm{H}_{2} \mathrm{O}_{2}$. We further verified the reaction mechanism of the enzyme-catalyzed coupling reaction. The probe is a promising candidate as a stable and safe fluorescent substrate in $\mathrm{H}_{2} \mathrm{O}_{2}$ sensing.
\end{abstract}

Keywords Hydrogen peroxide, aggregation-induced emission, fluorescence probe

(Received December 29, 2020; Accepted February 18, 2021; Advance Publication Released Online by J-STAGE April 23, 2021)

\section{Introduction}

Hydrogen peroxide $\left(\mathrm{H}_{2} \mathrm{O}_{2}\right)$ (biological level is about $0.48 \times 10^{-8}$ $\left.0.57 \times 10^{-8} \mathrm{M}\right)$, is a main reactive oxygen by-product produced in the metabolism of organisms and a common biomarker of oxidative stress. ${ }^{1-4}$ Many methods such as colorimetry, surface enhanced Raman spectroscopy, chromatographic analysis, chemiluminescence, fluorescence and electrochemical analysis have been developed. ${ }^{1-12}$ Among them, fluorescent probes have attracted wide concern, since they are cost-effective, highly sensitive and convenient to operate. However, most of fluorescent compounds are not photostable, and aggregation caused quenching (ACQ) often occurs in biological environments.

In recent years, fluorogens with a AIE (aggregation-induced emission) feature have been proposed in a construction of biochemical sensors. AIEgens are greatly emissive in an

X. L. and W. Y. contributed equally to this work.

$\dagger$ To whom correspondence should be addressed.

E-mail: mengmeng@nankai.edu.cn (M. M.); xycpumch@139.com (Y. X.) aggregated state, and therefore have significant resistance against photobleaching. ${ }^{13-18}$ The reported strategies for $\mathrm{H}_{2} \mathrm{O}_{2}$ AIEgens design have usually employed benzeneboronic acid to respond with hydrogen peroxide. ${ }^{19-22}$ Recently, approaches involving enzyme-catalyzed polymerization of AIEgen were proposed for $\mathrm{H}_{2} \mathrm{O}_{2}$ sensing. Wang et al. designed tyrosinefunctionalized tetraphenylethene (TPE-Tyr), with a TPE core as an AIE motif and four peripheral tyrosines as an enzyme substrate. Intermolecular cross-linking could occur under the HRP-catalyzed oxidative coupling of tyrosine moieties in the presence of hydrogen peroxide, leading to a "turn-on" AIE property. ${ }^{23}$ Yuan et al. used a similar strategy to develop enzyme-catalyzed AIE-active substrates by copper-mediated azide-alkyne click (CuAAC) polymerization. ${ }^{24}$ These strategies improve the aggregation of the AIEgens, but their synthesis usually requires multiple processes. We herein modify the AIE motif, tetraphenylethene (TPE), with $o$-phenylenediamine (TPETAF), which can be oxidated by $\mathrm{H}_{2} \mathrm{O}_{2}$ in HRP and form an intramolecular phenazine structure. ${ }^{25}$ Compared with a similar approach, the proposed strategy is simple and the TPE-TAF has shown a sensitive "turn-on" fluorescence in response to $\mathrm{H}_{2} \mathrm{O}_{2}$. The detection range is $10-100 \mu \mathrm{M}$, with a detection limit (LOD) of $3.39 \mu \mathrm{M}$, and the probe is highly specific against $\mathrm{H}_{2} \mathrm{O}_{2}$. 
a<smiles>Nc1ccc(C(c2ccccc2)c2cc(C(=O)c3ccccc3)ccc2N)cc1N</smiles>

b

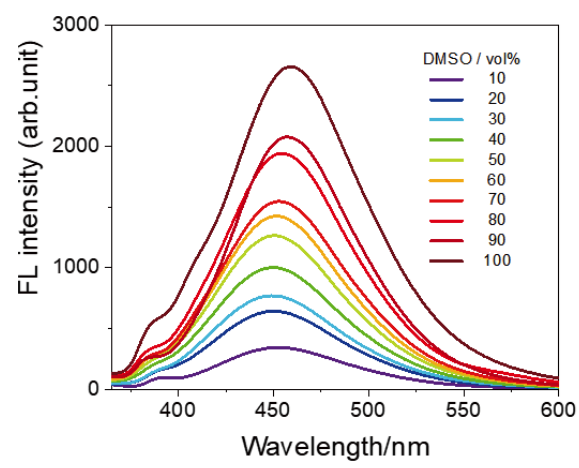

C

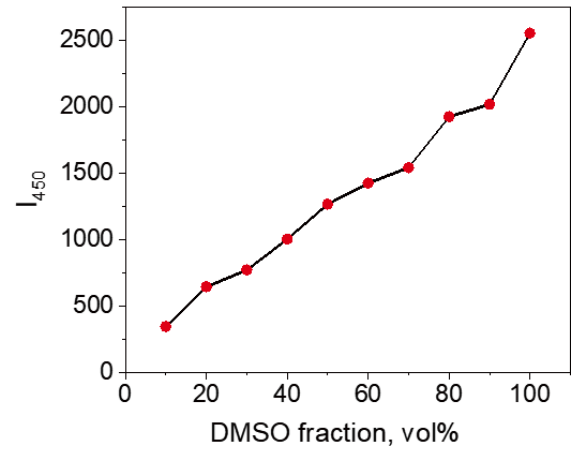

Fig. 1 Synthetic route of TPE-TAF (a); fluorescence emission spectra (b); fluorescence intensity (c) of TPE-TAF in DMSO with a varying water fraction $\left(\lambda_{\mathrm{ex}}=320 \mathrm{~nm}\right)$.

We further verified the reaction mechanism of the enzymecatalyzed coupling reaction, and demonstrated that the probe is a promising candidate as a fluorescent substrate in $\mathrm{H}_{2} \mathrm{O}_{2}$ sensing.

\section{Materials and Methods}

\section{Materials and instruments}

3,4-Diaminobenzophenone, ferrous sulfate, sodium hypochlorite, sodium nitrite, sodium nitrate, sodium dihydrogen phosphate, disodium hydrogen phosphate were purchased from Shanghai Saen Chemical Technology Co., Ltd. Horseradish peroxidase (HRP) was purchased from Beijing Zhijie Fangyuan Technology Co., Ltd. 1,2-Dinitrobenzen and a 30\% hydrogen peroxide $\left(\mathrm{H}_{2} \mathrm{O}_{2}\right)$ solution were from Beijing Yinuokai Technology Co., Ltd. Diphenylamine and $o$-phenylenediamine were from Bailingwei Technology Co., Ltd (Beijing, China).

The structure of synthesized compounds was validated by LC-MS (Agilent 6520 Q-TOF LC/MS, Agilent, USA) and 400 M NMR (Bruker, Germany). Characteristics of TPE-TAF were studied by using a fluorescence spectrophotometer (F4600, Hitachi) and transmission electron microscopy (Talos F200C, Czech Republic, USA). Dynamic size of TPE-TAF was measured by a Nanoparticle size analyzer (Nano-ZS, Malvern Instruments, UK). Fluorescence emission of TPE-TAF was observed by a laser scanning confocal microscope (TCS SP8, Leica, Germany).

\section{Synthesis of TPE-TAF}

Zinc powder $(1.7 \mathrm{~g}, 26.5 \mathrm{mmol})$ was dissolved in $30 \mathrm{~mL}$ of anhydrous THF and reacted with $1.43 \mathrm{~mL}$ of $\mathrm{TiCl}_{4}$ at $-10^{\circ} \mathrm{C}$ under $\mathrm{N}_{2}$ and refluxed for $2 \mathrm{~h}$. Then, 3,4-diaminobenzophenone $(1.40 \mathrm{~g}, 6 \mathrm{mmol})$ in $65 \mathrm{~mL}$ of THF was added and refluxed for $4 \mathrm{~h}$, followed by adding $100 \mathrm{~mL}$ of a $10 \% \mathrm{~K}_{2} \mathrm{CO}_{3}$ solution (Fig. 1a). The mixture was vigorously stirred for $5 \mathrm{~min}$, and then the crude product was filtrated to collect the organic layer. The aqueous layer was extracted by dichloromethane three times and combined with the organic aqueous. After being washed with water and dried with anhydrous $\mathrm{Na}_{2} \mathrm{SO}_{4}$, the organic solvent was removed to obtain a crude product. The crude product was purified by column chromatography (PE/EA $=1 / 2, \mathrm{v} / \mathrm{v})$ to obtain a yellow solid compound with yielding $40 \%$. ${ }^{1} \mathrm{H}-\mathrm{NMR}(400 \mathrm{MHz}, \mathrm{MeOD}) \delta 4.74(\mathrm{~s}, 8 \mathrm{H}), 6.13-$ $6.15(\mathrm{~m}, 2 \mathrm{H}), 6.27-6.31(\mathrm{~m}, 4 \mathrm{H}), 6.92(\mathrm{~s}, 10 \mathrm{H}){ }^{13} \quad \mathrm{C}-\mathrm{NMR}$ $(100 \mathrm{MHz}, \mathrm{MeOD}) \delta 145.03,139.64,135.75,133.51,133.19$, 131.01, 126.92, 125.36, 123.43, 119.74, 115.46. MS data, $\mathrm{m} / \mathrm{z}$ : calculated, 392.2; found, $393.250(\mathrm{M}+\mathrm{H})$ (Fig. S1).

\section{Morphology evaluation and working mechanism of TPE-TAF}

The experiments were performed in two groups: (1) TPE-TAF $(25 \mu \mathrm{M})$ dissolved in $10 \mathrm{mM}$ PBS ( $\mathrm{pH} 6.40,25^{\circ} \mathrm{C}, 10$ vol\% DMSO) with HRP $0.001 \mathrm{mg} / \mathrm{L}$; (2) TPE-TAF $(25 \mu \mathrm{M})$ with hydrogen peroxide $(100 \mu \mathrm{M})$ and HRP $(0.001 \mathrm{~g} / \mathrm{L})$ in $10 \mathrm{mM}$ PBS (pH $6.40,25^{\circ} \mathrm{C}, 10 \mathrm{vol} \% \mathrm{DMSO}$ ) at $25^{\circ} \mathrm{C}$. The particle size of the two TPE-TAF groups was then evaluated. To confirm the interaction mechanism of the probe molecule with hydrogen peroxide, we spiked $o$-phenylenediamine (OPD) and 1,2-dinitrobenzene $(m$-DNB) together, in which $o$-phenylenediamine was used as a competitive substrate and 1,2-dinitrobenzene as a control substrate.

\section{Results and Discussion}

\section{AIE properties of TPE-TAF}

Using a one-step McMurry reaction, we synthesized TPE-TAF with 3,4-diaminobenzophenone. The TPE-TAF showed good water solubility. Therefore, we detected the AIE features of the probe by increasing the fraction of DMSO. As the fraction increased, the fluorescence intensity of TPE-TAF at $450 \mathrm{~nm}$ was gradually elevated (Fig. 1b), which demonstrated a typical AIE behavior of TPE-TAF. Due to the low fluorescence in $10 \%$ DMSO, TPE-TAF was dissolved in 10\% DMSO for subsequent experiments. 
a

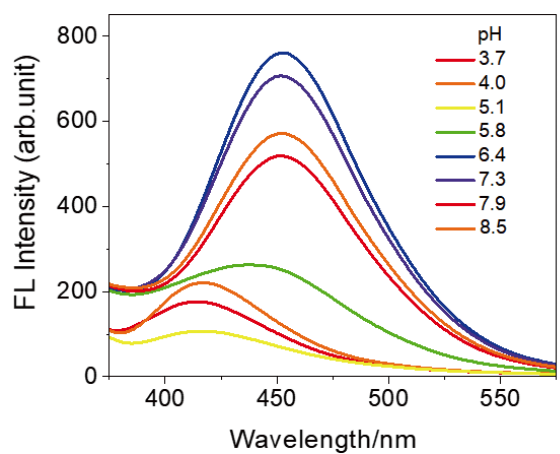

b

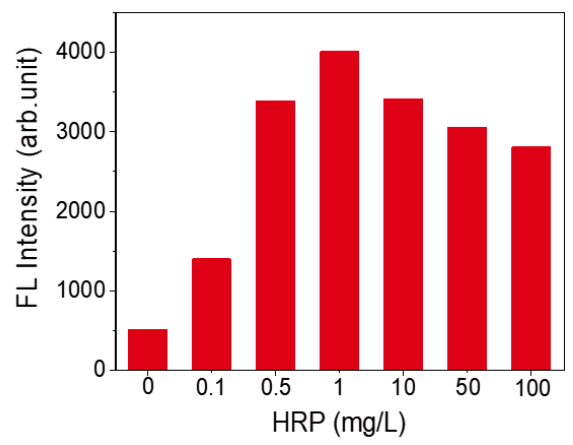

Fig. 2 (a) Fluorescence emission spectra of TPE-TAF $(25 \mu \mathrm{M})$ with hydrogen peroxide $(50 \mu \mathrm{M})$ and HRP $(1 \mathrm{mg} / \mathrm{mL})$ at $450 \mathrm{~nm}$ under different $\mathrm{pH}$ conditions; (b) fluorescence intensity of TPE-TAF $(25 \mu \mathrm{M})$ with hydrogen peroxide $(50 \mu \mathrm{M})$ and different concentrations of HRP.

a

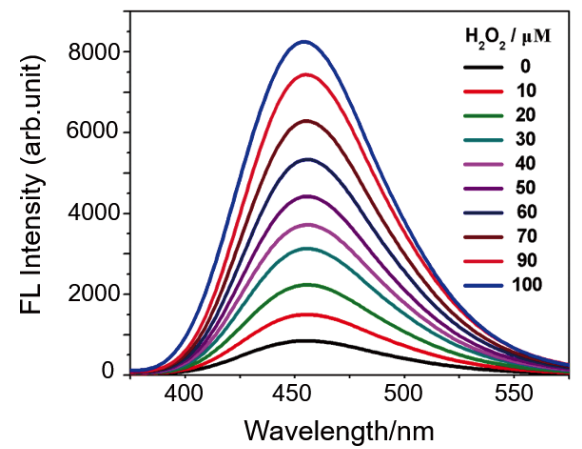

C

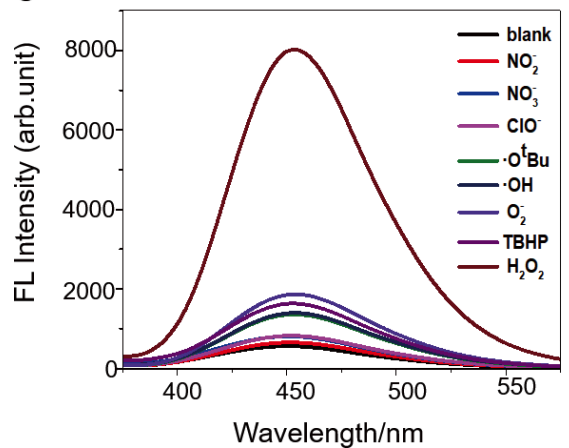

b

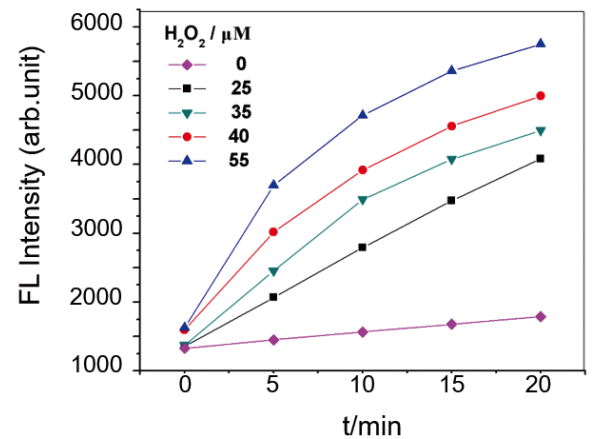

d

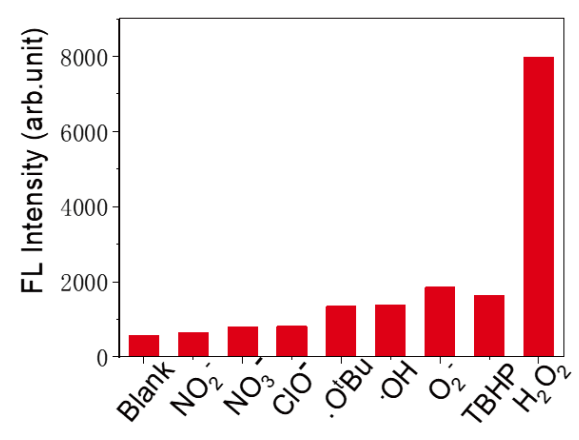

Fig. 3 (a) Fluorescence-emission spectra of TPE-TAF $(25 \mu \mathrm{M})$ with different concentrations of hydrogen peroxide; (b) fluorescence intensity of TPE-TAF $(5 \mu \mathrm{M})$ incubated with hydrogen peroxide $(0,25,35,40,55 \mu \mathrm{M})$ for different period of times; (c) fluorescence emission spectra of TPE-TAF with different reactive oxygen species; (d) fluorescence intensity of TPE-TAF with different reactive oxygen species.

\section{Characteristics of $\mathrm{H}_{2} \mathrm{O}_{2}$ sensing by TPE-TAF}

The optimal $\mathrm{pH}$ value for $\mathrm{H}_{2} \mathrm{O}_{2}$ sensing was investigated as follows: TPE-TAF $(25 \mu \mathrm{M})$ was incubated with $\mathrm{HRP}(1 \mathrm{mg} / \mathrm{L})$ and $\mathrm{H}_{2} \mathrm{O}_{2}(50 \mu \mathrm{M})$ with $10 \%$ DMSO in $10 \mathrm{mM}$ PBS. The fluorescence emission spectra showed a low FL intensity from $\mathrm{pH} 3.5$ to 5.1, but displayed high intensity starting from $\mathrm{pH} 5.1$. The highest FL intensity could be observed in the range of $\mathrm{pH}$ $6.4-7.4$ (Fig. 3a, Fig. S2), probably attributed to the remarkable crosslinking of TPE-TAF by HRP under the neutral $\mathrm{pH}$ range. These results showed that the probe can stably respond to $\mathrm{H}_{2} \mathrm{O}_{2}$ in biological environments.

To detect $\mathrm{H}_{2} \mathrm{O}_{2}$, we then optimized the HRP concentration. A PBS buffer (pH 6.4, $10 \mathrm{mM}, 10 \%$ DMSO) containing $25 \mu \mathrm{M}$ TPE-TAF, $50 \mu \mathrm{M} \mathrm{H} \mathrm{H}_{2} \mathrm{O}_{2}$ and different concentrations of HRP were reacted for $30 \mathrm{~min}$. As can be seen in Fig. 2b, there was nearly no fluorescent emission in the absence of HRP, indicating a negligible background interference. When the concentration of HRP reached $0.001 \mathrm{~g} / \mathrm{L}$, the fluorescence emission was the highest (Fig. S3). We next evaluated the dynamic sensing process by mixing $25 \mu \mathrm{M}$ TPE-TAF with $50 \mu \mathrm{M} \mathrm{H}_{2} \mathrm{O}_{2}$ and 
a

b

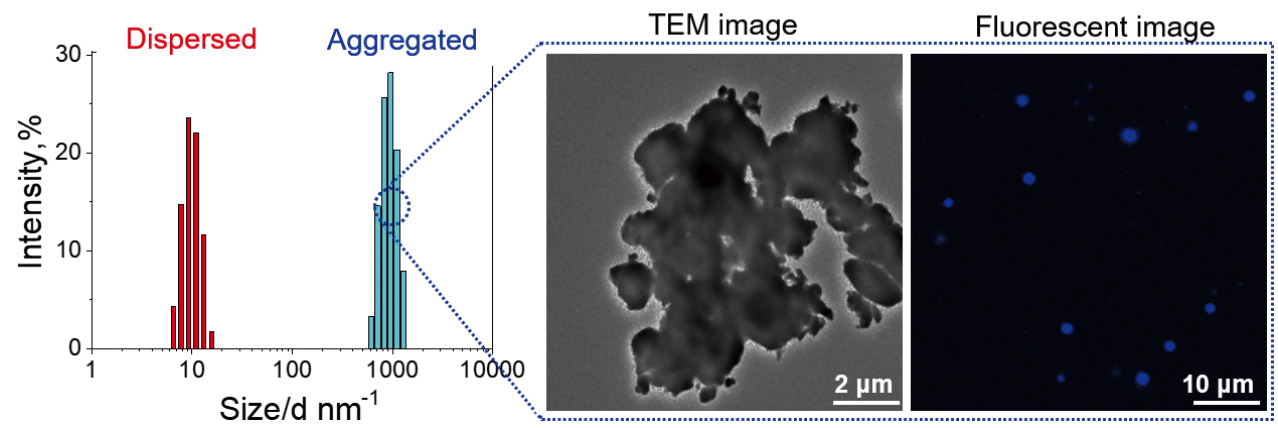

Fig. 4 (a) Particle size of dissolved TPE-TAF $(25 \mu \mathrm{M})$ and aggregated TPE-TAF in the presence of hydrogen peroxide $(100 \mu \mathrm{M})$; (b) TEM and confocal fluorescent image of the polymerized TPE-TAF aggregates $\left(\lambda_{\mathrm{ex}}=320 \mathrm{~nm}\right)$.

a

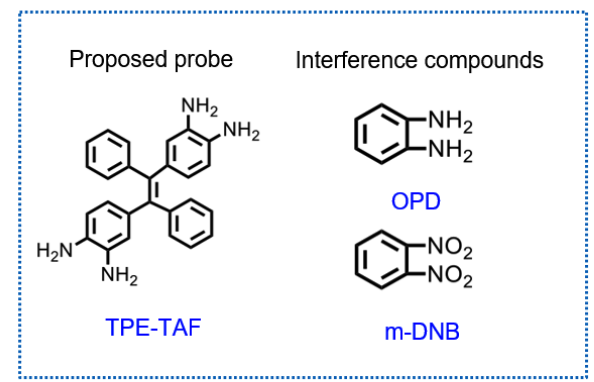

C

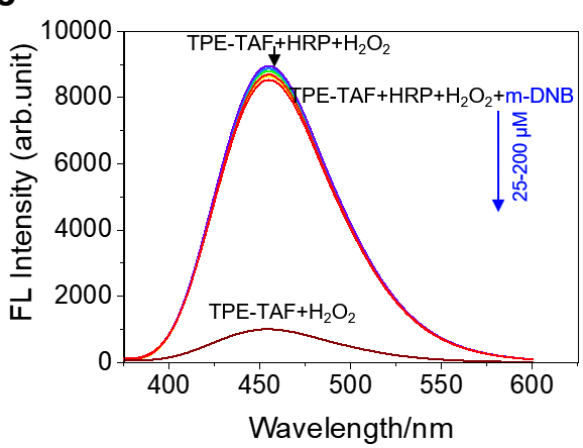

b

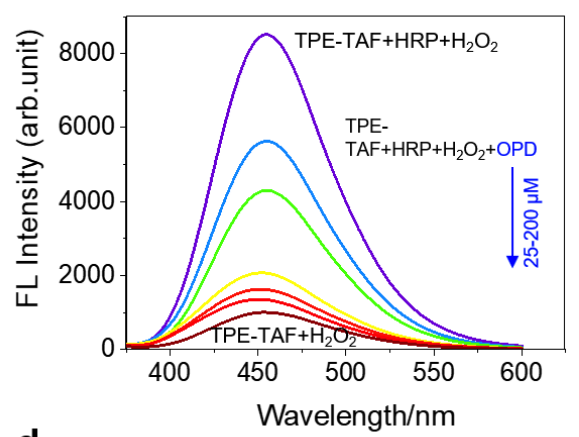

d

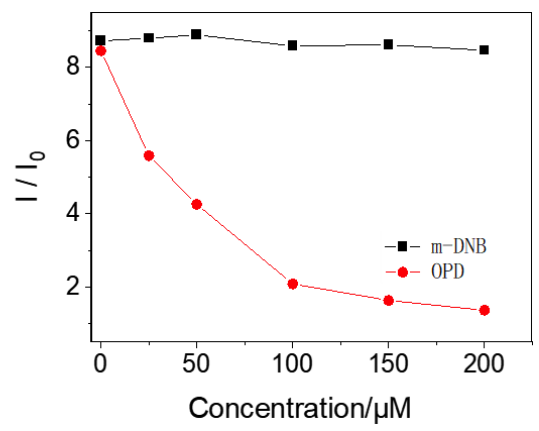

Fig. 5 Mechanism validation of TPE-TAF to $\mathrm{H}_{2} \mathrm{O}_{2}$. (a) Chemical structure of the competitive substrate $o$-phenylenediamine (OPD) and control substrate 1,2-dinitrobenzene ( $m$-DNB); (b) fluorescence emission spectra of TPE-TAF $(25 \mu \mathrm{M})$ with hydrogen peroxide $(100 \mu \mathrm{M})$ in different concentrations of OPD $(0,25,50,150,200 \mu \mathrm{M})$; (c) fluorescence emission spectra of TPE-TAF $(25 \mu \mathrm{M})$ with hydrogen peroxide $(100 \mu \mathrm{M})$ in different concentrations of $m$-DNB $(0,25,50,150$, $200 \mu \mathrm{M})$; (d) fluorescence emission spectra of TPE-TAF $(25 \mu \mathrm{M})$ with hydrogen peroxide $(100 \mu \mathrm{M})$ in different concentrations of $m$-DNB and $\operatorname{OPD}(0,25,50,150,200 \mu \mathrm{M})$.

$1 \mathrm{mg} / \mathrm{L} \mathrm{HRP}$. The fluorescence spectra of the reaction were measured every 5 min. As shown in Fig. 3, with a prolongation of the reaction time, the fluorescence intensity increased and reached a stable state after $30 \mathrm{~min}$.

Based on the optimal conditions, we further studied the fluorescence intensity changes for different concentrations of $\mathrm{H}_{2} \mathrm{O}_{2}$. As shown in Fig. 3, for a blank group without $\mathrm{H}_{2} \mathrm{O}_{2}$, the intensity of TPE-TFA was very low after incubation for $20 \mathrm{~min}$. As the concentrations of $\mathrm{H}_{2} \mathrm{O}_{2}$ increased, the FL intensity was gradually enhanced. The FL intensity at $455 \mathrm{~nm}$ correlated well with the concentration of hydrogen peroxide from $0-100 \mu \mathrm{M}$
$\left(R^{2}=0.996\right)$. The detection limit (LOD) was calculated to be $3.39 \mu \mathrm{M}(\mathrm{S} / N=3, n=11)$ (Fig. S4).

To evaluate the sensing specificity, we tested the fluorescence changes of the probe interacting with various active oxides, such as hydroxyl radicals (HO-), peroxy-tert-butanol (TBHP), tertbutoxy $\left(\cdot \mathrm{O}^{t} \mathrm{Bu}\right)$, peroxy anion $\left(\mathrm{O}_{2}^{-}\right)$, as well as hypochlorite anion $\left(\mathrm{ClO}^{-}\right)$, nitrite $\left(\mathrm{NO}_{2}^{-}\right)$and nitrate $\left(\mathrm{NO}_{3}^{-}\right)$(Fig. 3). The reaction of hydrogen peroxide with the TPE-TFA caused the most obvious increment of the fluorescence intensity compared to other compounds, demonstrating an excellent specificity of the probe with little interference by other active molecules. 
Morphology and reaction mechanism for the $\mathrm{H}_{2} \mathrm{O}_{2}$ sensing

We then investigated the morphology changes of TPE-TAF $(25 \mu \mathrm{M})$ after binding with hydrogen peroxide. Under the reaction of $1 \mathrm{mg} / \mathrm{L} \mathrm{HRP}$ and $100 \mu \mathrm{M} \mathrm{H}_{2} \mathrm{O}_{2}$, the particle size of the probe increased from $5 \mathrm{~nm}$ to $1 \mu \mathrm{m}$ (Fig. 4a), and the aggregated particles were highly emissive (Fig. 4b).

We further validated the proposed mechanism for the enzymecatalyzed crosslinking of TPE-TAF. Substrate competition experiments were conducted by adding OPD or m-DNB into the sensing system. As can be seen in Fig. 5, the fluorescence intensity of TPE-TFA decreased with an increase of the OPD concentration, but did not change with the concentration of $m$-DNB being elevated. This result indicated that OPD might compete with the TPE-TFA, and thus inhibited the crosslinking reaction and reduced the fluorescence intensity induced by TPETFA aggregation.

\section{Conclusions}

In this work, we modified tetraphenylethene (TPE) with $o$-phenylenediamine (TPE-TAF) for $\mathrm{H}_{2} \mathrm{O}_{2}$ sensing, which can be oxidated by $\mathrm{H}_{2} \mathrm{O}_{2}$ in HRP and form an intramolecular phenazine structure, which thus exhibited a "turn-on" AIE feature. Compared with similar approaches, the proposed strategy is simple and convenient. The detection range for $\mathrm{H}_{2} \mathrm{O}_{2}$ is $10-100 \mu \mathrm{M}$ with a detection limit (LOD) of $3.39 \mu \mathrm{M}$, and the probe is highly specific against $\mathrm{H}_{2} \mathrm{O}_{2}$. We finally demonstrated the reaction mechanism of the enzyme-catalyzed coupling reaction. As a summary, the probe is a promising candidate as a fluorescent substrate in $\mathrm{H}_{2} \mathrm{O}_{2}$ sensing.

\section{Conflicts of Interest}

All other authors declare no competing interests.

\section{Acknowledgements}

This work was supported by the Natural Science Foundation of China of Tianjin City (18JCYBJC24800), National Natural Science Foundation of China (No. 81573390), Beijing Natural Science Foundation (7194312), Beijing Nova Program (Z201100006820127), Tsinghua University-Peking Union Medical College Hospital Collaboration Project (PTQH201911583), Beijing Key Laboratory for Mechanisms Research and Precision Diagnosis of Invasive Fungal Diseases.

\section{Supporing Information}

Supplementary material related to this article can be found in the online version.

\section{References}

1. M. Ren, B. Deng, and J. Y. Wang, Biosens. Bioelectron., 2016, 79, 237.

2. S. Ge, W. Liu, H. Liu, F. Liu, J. Yu, M. Yan, and J. Huang, Biosens. Bioelectron., 2015, 71, 456.

3. Z. H. Bai, G. Y. Li, and J. T. Liang, Biosens. Bioelectron., 2016, 82, 185.

4. J. Peng, X. F. Hou, and F. Zeng, Biosens. Bioelectron., 2017, 94, 278.

5. S. R. Cao, L. Zhang, and Y. Chai, Biosens. Bioelectron., 2013, 42, 532.

6. S. Chen, X. Hai, and X. W. Chen, Anal. Chem., 2014, 86, 6689.

7. V. S. Lin, A. R. Lippert, and C. J. Chang, Proc. Natl. Acad. Sci. U. S. A., 2013, 110, 7131.

8. W. M. Xuan, C. Q. Sheng, and Y. T. Cao, Angew. Chem., Int. Ed., 2012, 51, 2282.

9. L. L. Qu, Y. Y. Liu, and S. H. He, Biosens. Bioelectron., 2016, 77, 292.

10. H. X. Dai, W. J. Lu, and X. W. Zuo, Biosens. Bioelectron., 2017, 95, 131.

11. J. Ju and W. Chen, Anal. Chem., 2014, 87, 1903.

12. Y. B. Tsaplev, J. Anal. Chem., 2012, 67, 514.

13. J. Mei, Y. N. Hong, and J. W. Y. Lam, Adv. Mater., 2014, $26,5429$.

14. J. Mei, N. L. C. Leung, and R. T. K. Kwok, Chem. Rev., 2015, 115, 11718.

15. X. G. Gu, R. T. K. Kwok, and J. W. Y. Lam, Biomaterials, 2017, 146, 115.

16. Y. N. Hong, J. W. Y. Lam, and B. Z. Tang, Chem. Soc. Rev., 2011, 40, 5361.

17. J. Mei, Y. H. Huang, and H. Tian, ACS Appl. Mater. Interfaces, 2018, 10, 12217.

18. G. X. Feng and B. Liu, Small, 2016, 12, 6528.

19. A. R. Lippert, G. C. V. D. Bittner, and C. J. Chang, Acc. Chem. Res., 2011, 44, 793.

20. J. X. Huang, T. T. Li, and R. L. Liu, Sens. Actuators, B, 2017, 248, 257.

21. G. J. Liu, Z. Long, and H. J. Lv, Chem. Commun., 2016, 52, 10233.

22. Z. G. Song, R. T. K. Kwok, and D. Ding, Chem. Commun., 2016, 52, 10076.

23. X. R. Wang, J. M. Hu, and G. Y. Zhang, J. Am. Chem. Soc., 2014, 136, 9890.

24. Y. Y. Yuan, W. B. Wu, and S. D. Xu, Chem. Commun., 2017, 53, 5287.

25. S. Huang, L. M. Wang, and C. S. Huang, Sens. Actuators, $B$, 2016, 234, 255 . 